\title{
Thermoplastic Polyurethanes-Fumed Silica Composites: Influence of NCO/OH in the Study of Thermal and Rheological Properties and Morphological Characteristics
}

\author{
José Vega-Baudrit'1,2, Sergio Madrigal Carballo² \\ and José Miguel Martín Martínez ${ }^{3}$ \\ ${ }^{1}$ Laboratorio Nacional de Nanotecnología LANOTEC-CeNAT, \\ ${ }^{2}$ Laboratorio de Polimeros POLIUNA-UNA, \\ ${ }^{3}$ Laboratorio de Adhesión y Adhesivos, Universidad de Alicante, \\ 1,2Costa Rica \\ ${ }^{3}$ España
}

\section{Introduction}

Thermoplastic polyurethanes (TPU's) are a multipurpose group of phase segmented polymers that have good mechanical and elastic properties and hardness. Usually, TPU's exhibit a two-phase microstructure, which arises from the chemical incompatibility between the soft and the hard segments. The hard rigid segment segregates into a glassy or semicrystalline domain and the polyol soft segments form amorphous or rubbery matrices, in which the hard segments are dispersed (Oertel, 1993). Many factors influence in the separation of phases as the molecular weight, the segmental length, the crystallizability of the segment, the overall composition and the intra- and inter-segments interactions. Fumed nanosilicas are added to increase the thermal, rheological and mechanical properties of TPU’s (Maciá-Agulló et al., 1992; Jaúregui-Belogui et al., 1999; Jaúregui-Belogui et al., 1999; Torró-Palau et al., 2001, Péres-Limaña et al., 2001).

When hydrophilic fumed nanosilica is added, the degree phase separation increases due to the interaction hydrogen-bonded between silanol groups on the nanosilica surface and soft segments of the TPU. Therefore, the segmental incompatibility on the TPU is increased with the presence of the hydrophilic nanosilicas. Recent studies have demonstrated that the use of this kind of materials able to form hydrogen-bonds result in less direct interactions between phases, causing a higher phase separation. Furthermore, the interactions between silanol and carbonyl groups are weaker than those between $\mathrm{NH}$ and ester carbonyl groups, then silica addition increases the polyester chain mobility and, it allows to become more ordered in relation to the TPU without silica (Sánchez-Adsuar et al., 2000; Tien et al., 2001; Nunes et al., 2000; Nunes et al., 2001).

The aim of this paper is to study the effect of incorporating hydrophilic fumed nanosilica in the formulation of polyurethane adhesives with different $\mathrm{NCO} / \mathrm{OH}$ to improve its thermal, rheological and adhesive properties. The hypothesis is that the degree of polyurethane 
phase segregation was affected by the presence of silica and the formation of hydrogen bonds. Therefore, there should be a variation of properties in polyurethanes in response to the presence of dispersed silica.

In recent papers are showed the results of evaluating these samples using thermal, rheological and mechanical analysis, and adhesion tests (Vega-Baudrit et al., 2006; NavarroBañón et al., 2005; Vega-Baudrit et al., 2008; Vega-Baudrit et al., 2009).

\section{Materials and methods}

Fumed silica (nanosilica HDK N20) was manufactured by Wacker-Chemie (Burghausen, Germany). The nominal primary particle size in all nanosilicas was $7 \mathrm{~nm}$. According to Wacker-Chemie, the nominal specific surface area of all nanosilicas was $200 \mathrm{~m}^{2} / \mathrm{g}$ and $100 \%$ of silanol groups.

The TPU was prepared using the prepolymer method. The prepolymer was obtained by reacting the polyadipate of 1,4-butanediol $\left(M_{\mathrm{W}}=2440\right.$ Daltons) with 4,4-diphenyl methane diisocyanate - MDI; using different isocyanate/macroglycol equivalent ratios $(1,05 ; 1,15$; 1,25). 1,4-butanediol was used as chain extender. High purity solid MDI was supplied by Aldrich (Cat. 25.643-9), a mixture of $98 \mathrm{wt} \%$ of the 4,4'-isomer and $2 \mathrm{wt} \%$ of the 2,4'-isomer. The NCO content of the prepolymer was determined by titration with dibutylamine (UNEEN 1242 standard). The polyadipate of 1,4-butanediol (Hoopol F-530) was supplied by Hooker S.A. (Barcelona, Spain) and was heated for 4 hours at $70^{\circ} \mathrm{C}$ under reduced pressure (5 Torr) to remove the residual water. The 1,4-butanediol was supplied by Aldrich (Cat. B8, 480-7) and was dried using $4 \AA$ molecular sieves. To avoid crosslinking reactions during polyurethane synthesis, the reaction temperature was kept below $65^{\circ} \mathrm{C}$ under a stirring speed of $80 \mathrm{rpm}$. The synthesis of the polyurethane was carried out in dry nitrogen atmosphere to avoid the presence of water in the reactor. The prepolymers containing unreacted isocyanate ends were completely reacted with the necessary stoichiometric amount of 1,4-butanediol. The reaction time was 2 hours.

TPU solutions were prepared by mixing $20 \mathrm{wt} \%$ solid polyurethane and $2 \mathrm{wt} \%$ nanosilica with 2-butanone in a Dispermix DL-A laboratory mixer, provided with a Cowles mechanical stirrer (diameter $=50 \mathrm{~mm}$ ) and a water jacket to maintain the temperature at $25^{\circ} \mathrm{C}$ during the preparation of the adhesives. This preparation was carried out in two consecutive stages: i) the nanosilica was mixed for $15 \mathrm{~min}$ at $2500 \mathrm{rpm}$ with $1 / 3$ butanone volume required. ii) the TPU and 2/3 butanone volume were added to the previous solution, stirring the mixture for $2 \mathrm{~h}$ at $2000 \mathrm{rpm}$. TPU solutions were kept in a hermetic container until use. A TPU solution without silica was also prepared as control. Most of the properties of the polyurethanes were measured using solid films, which were prepared by placing about 100 $\mathrm{cm}^{3}$ of solution in a mould and allowing a slow evaporation of the solvent at room temperature during 2 days. The polyurethane films obtained were about 0.7 to $0.9 \mathrm{~mm}$ thick. The nomenclature of the polyurethane-nanosilica mixtures were PU105, PU115 and PU125 (according with $\mathrm{NCO} / \mathrm{OH}$, respectively).

\subsection{Experimental techniques}

Samples were characterized by FTIR with Attenuated Total Reflectance (ATR), Differential Scanning Calorimetry DSC, Dynamic Mechanical Thermal Analysis DMTA, Transmission Electronic Microscopy TEM and X-ray Diffraction XRD. 
The IR spectra of the polyurethane films were obtained in the transmission mode using a Bruker Tensor 27 spectrophotometer. Under the experimental conditions used, the signal/noise ratio of the equipment was $0.04 \%$ transmittance (at $2000 \mathrm{~cm}^{-1}$ ). The resolution was $4 \mathrm{~cm}^{-1}$ and 80 scans were recorded and averaged.

DSC experiments were carried out in a TA instrumentDSC Q100 V6.2. Aluminium pans containing $12-15 \mathrm{mg}$ of sample were heated from $-80^{\circ} \mathrm{C}$ to $80^{\circ} \mathrm{C}$ under nitrogen atmosphere. The heating rate was $10^{\circ} \mathrm{C} / \mathrm{min}$. The first heating run was carried out to remove the thermal history of the samples. From the second heating run, the glass transition temperature (Tg), the melting temperature $(\mathrm{Tm})$, the crystallization temperature $(\mathrm{Tc})$, the melting enthalpy $(\Delta \mathrm{Hm})$, and the crystallization enthalpy $(\Delta \mathrm{Hc})$ of the TPUs were obtained. The crystallization rate was estimated by melting the polyurethane film at $100{ }^{\circ} \mathrm{C}$, followed by a sudden decrease to $25^{\circ} \mathrm{C}$ and the evolution of heat with time under isothermal conditions was monitored for $30 \mathrm{~min}$ at $25^{\circ} \mathrm{C}$ until a crystallization peak appeared.

The viscoelastic properties of the polyurethanes were measured in a Rheometric Scientific DMTA Mk III instrument using the two-point bending mode (single cantilever). The experiments were carried out by heating the sample from $-80^{\circ} \mathrm{C}$ to $100{ }^{\circ} \mathrm{C}$, using a heating rate of $5^{\circ} \mathrm{C} / \mathrm{min}$, a frequency of $1 \mathrm{~Hz}$ and a strain of $64 \mathrm{~mm}$ peak-peak.

A JEOL JEM-2010 instrument was used to analyze the morphology of the nanosilicas; an acceleration voltage of $100 \mathrm{kV}$ was used. The nanosilicas were placed directly into the grid specially design for TEM analysis.

The polyurethane crystallinity was determined using Seifert model JSO-DEBYEFLEX 2002 equipment. This equipment was provided with a copper cathode and a nickel filter, and the monochromatic radiation of copper (Ka) was used as the X-ray source $(\lambda=1,54 \AA)$. A range of diffraction angles $(2 \theta)$ from $5^{\circ}$ to $90^{\circ}$ were used in the experiments.

\section{Results and discussion}

Recent studies (Nunes et al., 2000; Nunes et al., 2001; Vega-Baudrit et al., 2006; NavarroBañón et al., 2005; Vega-Baudrit et al., 2008; Vega-Baudrit et al., 2009) have demonstrated that the addition of fillers as silica able to form hydrogen-bonds result in less direct interactions between phases, causing a higher degree of phase separation in the polyurethane. On the other hand, the interactions between the silanol groups and the carbonyl groups in the polyurethane are weaker than those between the $\mathrm{N}-\mathrm{H}$ and ester carbonyl groups, and therefore the silica addition increases the polyester chain mobility in the polyurethane allowing the creation of more ordered phases with respect to the polyurethane without silica.

\subsection{Characterization of polyurethanes with different $\mathrm{NCO} / \mathrm{OH}$}

Synthesized thermoplastic polyurethanes (TPU) with different $\mathrm{NCO} / \mathrm{OH}$ were characterized by IR-FTIR spectroscopy (Figure 1). No significant differences among the TPU, except for a higher intensity of the bands between 900 and $1300 \mathrm{~cm}^{-1}$, which increases with increasing the $\mathrm{NCO} / \mathrm{OH}$. Similarly, there is no characteristic band of the isocyanate groups (-NCO) close to $2250 \mathrm{~cm}^{-1}$, indicating that the reaction was complete. 


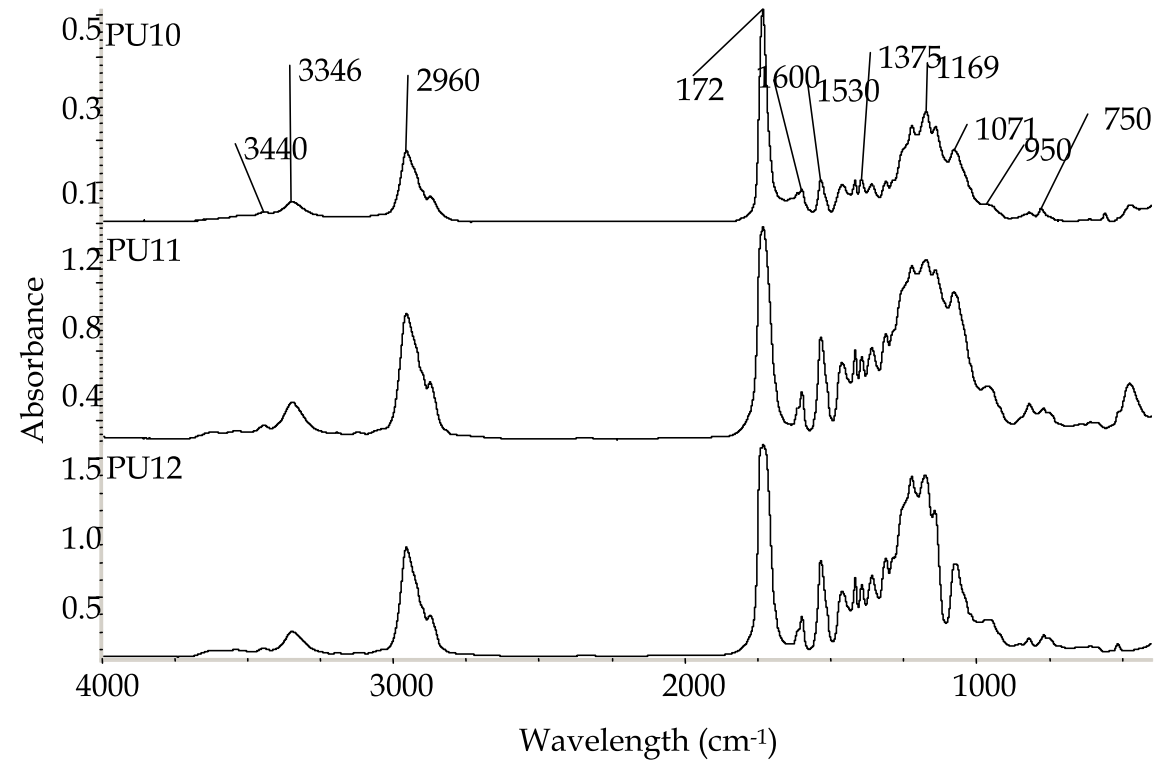

Fig. 1. FTIR of synthesized thermoplastic polyurethanes (TPU) with different $\mathrm{NCO} / \mathrm{OH}$.

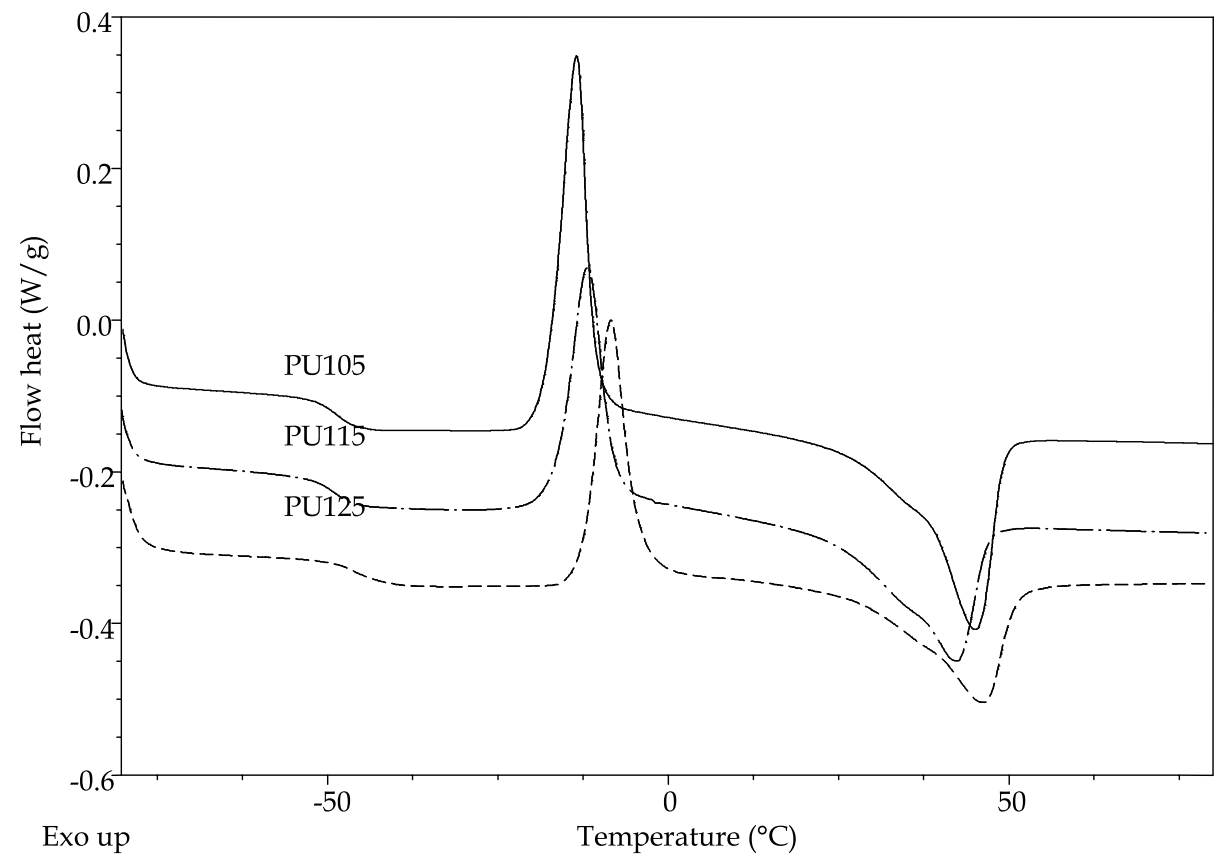

Fig. 2. DSC thermograms of synthesized thermoplastic polyurethanes (TPU) with different $\mathrm{NCO} / \mathrm{OH}$ 
In DSC thermograms (Figure 2), first glass transition temperature $\left(\mathrm{T}_{\mathrm{g} 1}\right)$ is close to $-48^{\circ} \mathrm{C}$ and is associated with soft segments of TPU. From -8 to $-13^{\circ} \mathrm{C}$ is showed the crystallization of soft segments, with an enthalpy of crystallization located between -20 and $-26 \mathrm{~J} / \mathrm{g}$. Also, close to $46^{\circ} \mathrm{C}$, it shows the melting temperature of soft segments, with a melting enthalpy of approximately $26 \mathrm{~J} / \mathrm{g}$. Finally, a second DSC thermogram carried out up to $300{ }^{\circ} \mathrm{C}$ shows a second glass transition temperature $\left(\mathrm{T}_{\mathrm{g} 2}\right)$ close to $250{ }^{\circ} \mathrm{C}$, which corresponds to the hard segments. Figure 3 shows parallel plate rheology - storage modulus $\left(G^{\prime}\right)$ and loss $\left(G^{\prime \prime}\right)$ as a function of temperature - of sample PU105.

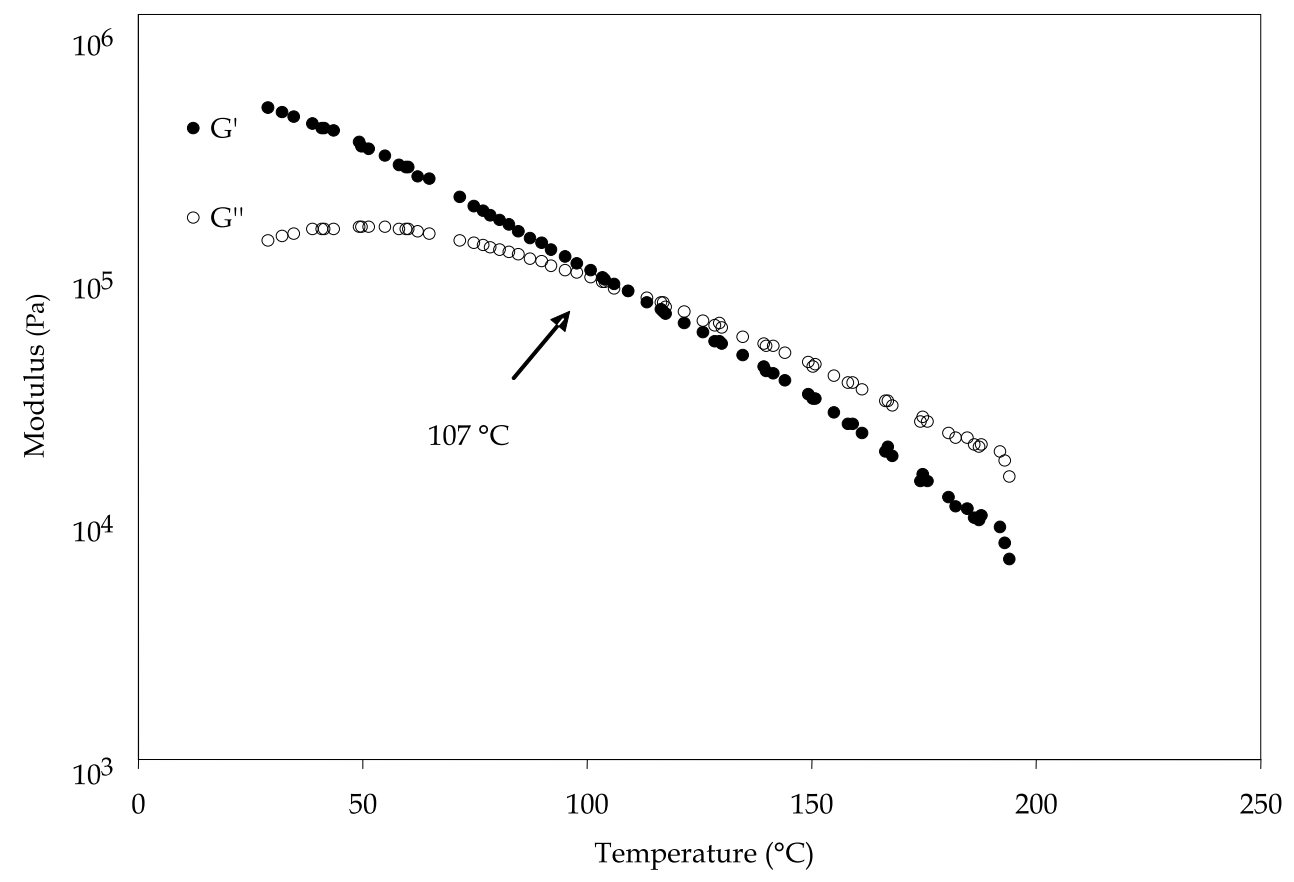

Fig. 3. Storage modulus (G') and loss (G') of sample PU105.

Figure 4 shows the storage modulus $\mathrm{G}^{\prime}$ for samples with different $\mathrm{NCO} / \mathrm{OH}$. For $\mathrm{G}^{\prime}$, there was an increase in the entire temperature range with increasing $\mathrm{NCO} / \mathrm{OH}$. The same situation occurs with the loss modulus throughout the temperature range, the material with an $\mathrm{NCO} / \mathrm{OH}$ of 1.05 has the lowest value. It is noted that increasing this ratio increases the value of the temperature of crossover between the modules, due to higher content of hard segments in TPU. Also, the higher modulus crossover between $G^{\prime}$ and $G^{\prime \prime}$ is presented by the polyurethane with the $\mathrm{NCO} / \mathrm{OH}$ of 1.25 . The difference between the two polyurethanes in the form of crossing is not significant.

It is expected that the sample with the highest ratio $\mathrm{NCO} / \mathrm{OH}$, - which has the highest hard segment content- present the greatest values in the storage and loss modules, and an increase in temperature and modulus of softening due to mixture of phases. As determined by IR-FTIR spectroscopy (Table 1), with increasing $\mathrm{NCO} / \mathrm{OH}$ increases the degree of phase 
separation (DPS), is a greater mobility of the polymer chains, so it is more ordered, crystalline, and both thermal and rheological properties are improved.

\begin{tabular}{|c|l|l|l|}
\hline NCO/OH & 1,05 & 1,15 & 1,25 \\
\hline DPS & 83,3 & 86,4 & 88,6 \\
\hline
\end{tabular}

Table 1. Degree phase separation (DPS) for samples with different NCO/OH.

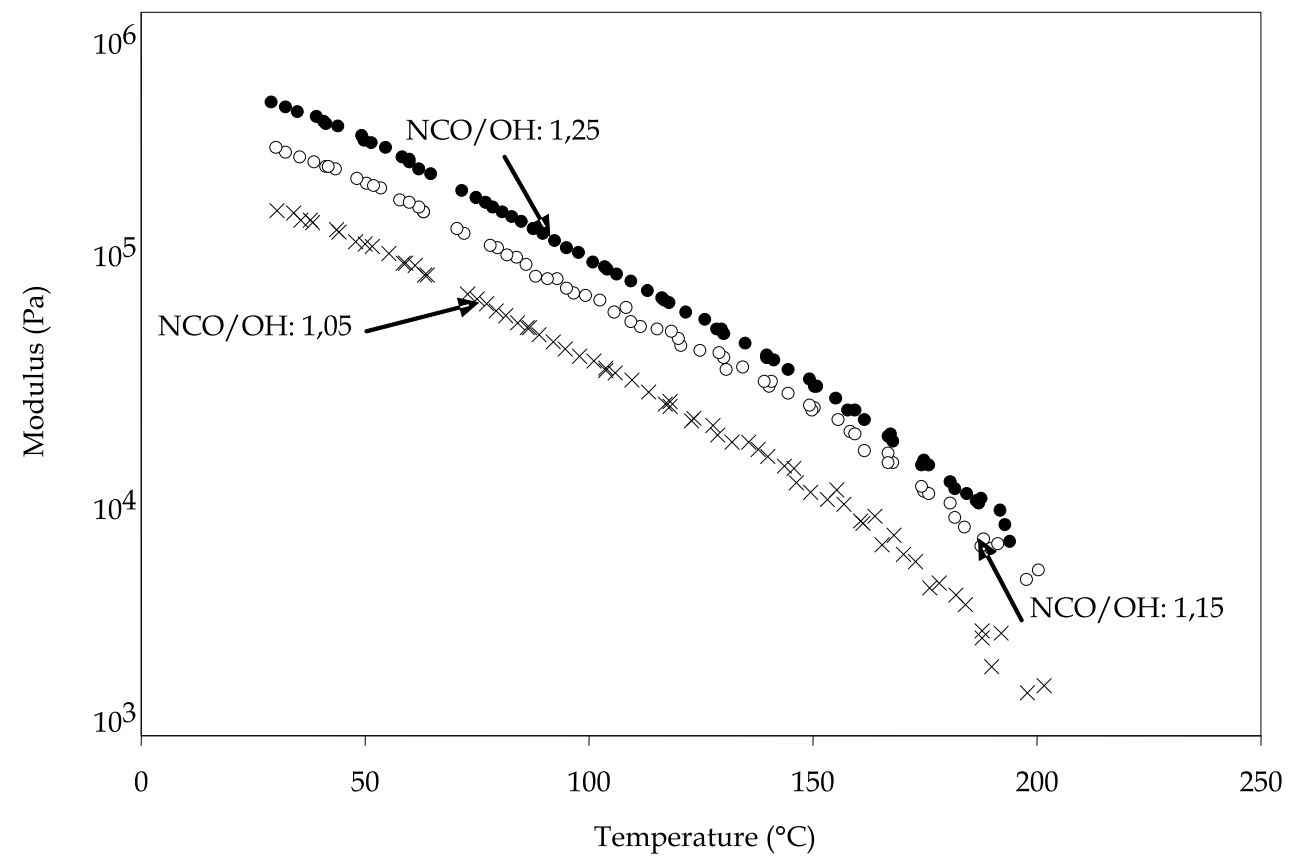

Fig. 4. Storage modulus $\mathrm{G}^{\prime}$ for samples with different $\mathrm{NCO} / \mathrm{OH}$.

\subsection{Characterization of polyurethane adhesives containing fumed silica}

TPU's with different $\mathrm{NCO} / \mathrm{OH}$ and containing fumed silica were analyzed by transmission electron microscopy-TEM (Figure 5). When NCO/OH is increased, DPS in TPU's is increased, too. Samples with fumed silica (PU105, PU115, and PU125) show an increase of DPS (Figure 6). This effect, as expected, is less evident in samples with lower $\mathrm{NCO} / \mathrm{OH}$, where there are light and dark areas, corresponding to the phases of hard and soft segments, respectively. That is, the material is less affected by the presence of fumed silica, and has the lowest phase segregation. Moreover, the degree of aggregation of silica increases with increasing the $\mathrm{NCO} / \mathrm{OH}$ in the TPU's. 
Thermoplastic Polyurethanes-Fumed Silica Composites: Influence of

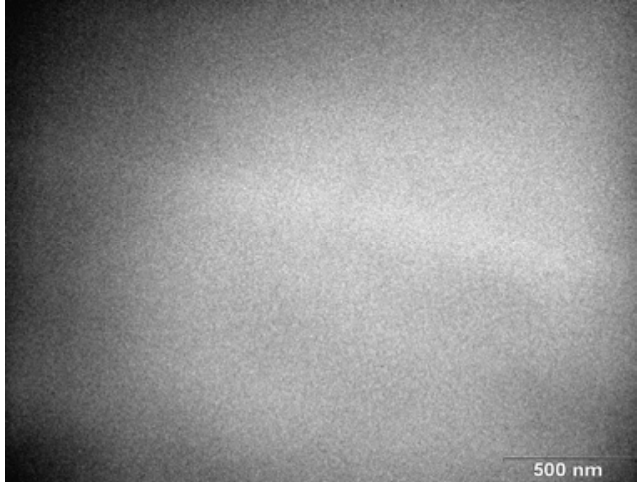

(a)

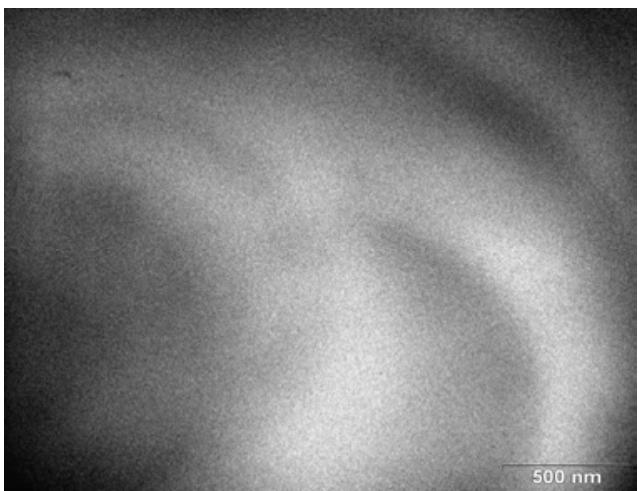

(c)

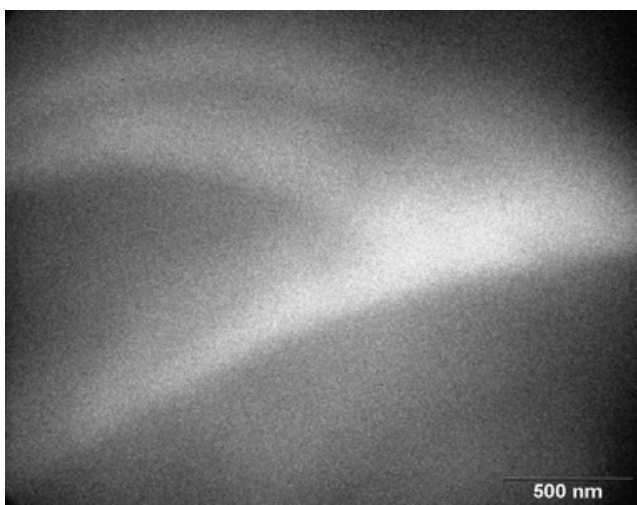

(e)

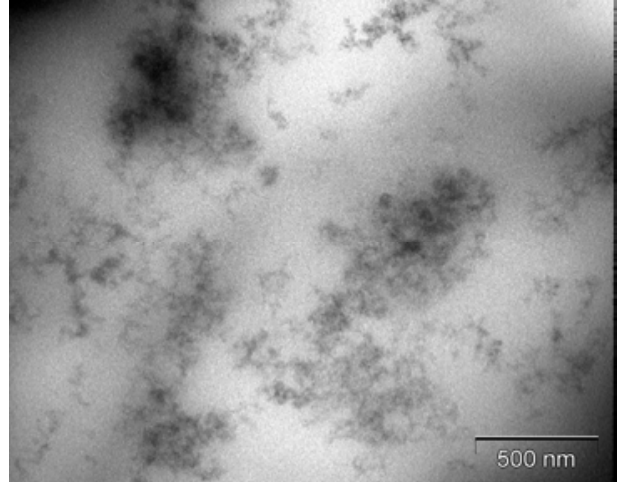

(b)

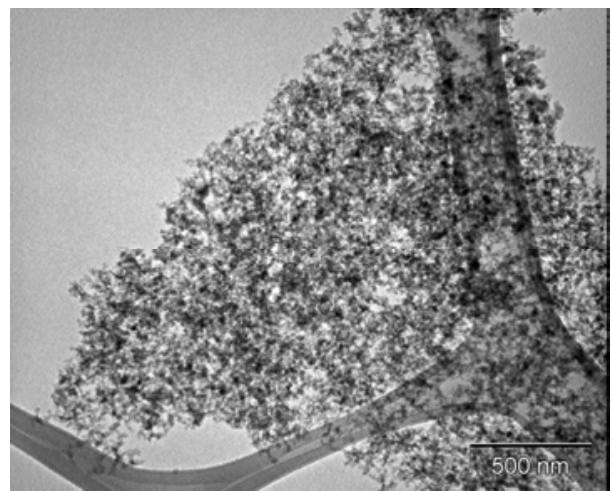

(d)

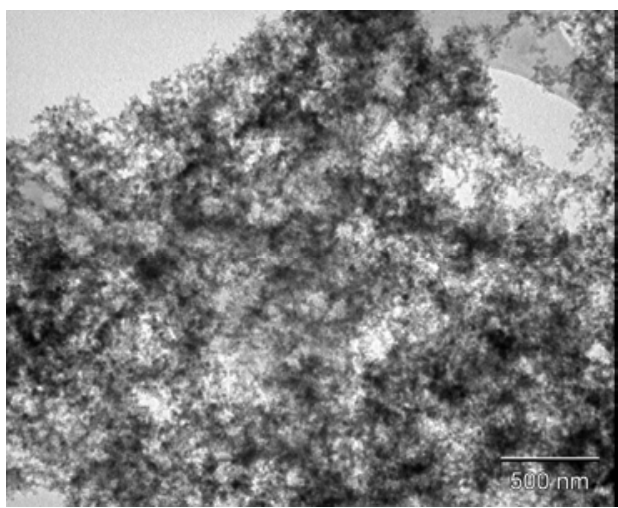

(f)

(a) TPU with NCO/OH of 1,05 without silica, (b) PU105, (c) TPU with NCO/OH of 1,15 without silica, (d) PU115, (e) TPU with NCO/OH of 1,25 without silica, (f) PU125

Fig. 5. TEM of TPU with different $\mathrm{NCO} / \mathrm{OH}$. 
To quantify the effect of phase segregation, we used the IR-FTIR spectroscopy. We calculated the degree of phase segregation (DPS) and the degree of phase mixing (DPM) (Torró-Palau et al., 2001, Péres-Limaña et al., 2001). The addition of fumed silica does not alter the chemical structure of TPU.

TPUS's without silica, with increasing of $\mathrm{NCO} / \mathrm{OH}$, DPS is increased, although it increases the content of hard segments of polyurethane. With the addition of silica to polyurethane, the DPS is favored in all samples. Silanol groups increases the possibility to produce hydrogen bonds in polymer, so the links inter-urethane, more favored energetically, interact to a greater extent and promotes greater interaction between the polyurethane soft segments, resulting in increased segregation phase between hard and soft segments of TPU.

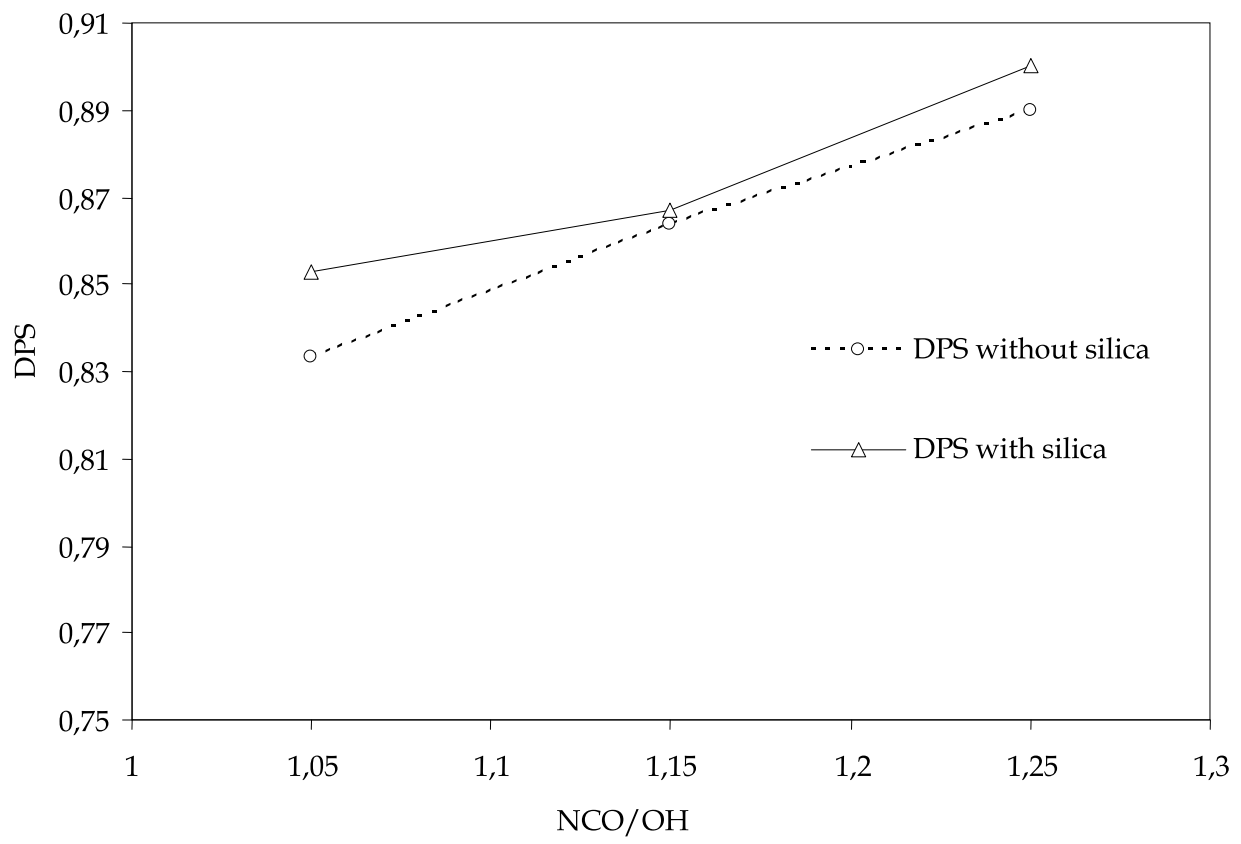

Fig. 6. Samples with and without silica with different $\mathrm{NCO} / \mathrm{OH}$

To study the interaction between TPU with different $\mathrm{NCO} / \mathrm{OH}$ and silica, thermal properties and crystallinity were studied. Differential scanning calorimetry (DSC) and the Xray diffraction were used (Figures 7 to 12).

As mentioned, the first glass transition is associated with soft segments of polyurethane. For the TPU synthesis, we used a polyol whose chains are less polar. It is expected that as the $\mathrm{NCO} / \mathrm{OH}$, increase the repulsion between hard and soft segments, and increase DPS. TPU's will present a greater order and therefore will be more crystalline. TPU's without silica, show an increase of $\mathrm{T}_{\mathrm{g} 1}$ as a response of increased in DPS (Figure 8). By incorporating fumed silica, the values of the glass transition temperature decrease over the polyurethanes do not contain silica. 
In TPU's with silica, the association-dissociation equilibrium of the hydrogen bond is favored toward the formation of more hydrogen bonds, specifically towards the formation of more interactions between the hard segments at the expense of the rupture of interactions between hard and soft segments. These interactions are stronger than interactions between soft segments themselves and silanol groups, so that TPU, despite the establishment of interactions between soft segments, they are less energetic than those between hard and soft segments, so that the polymer need less energy to reach the glass transition, crystallization or melting, these phenomena occur at lower temperatures.

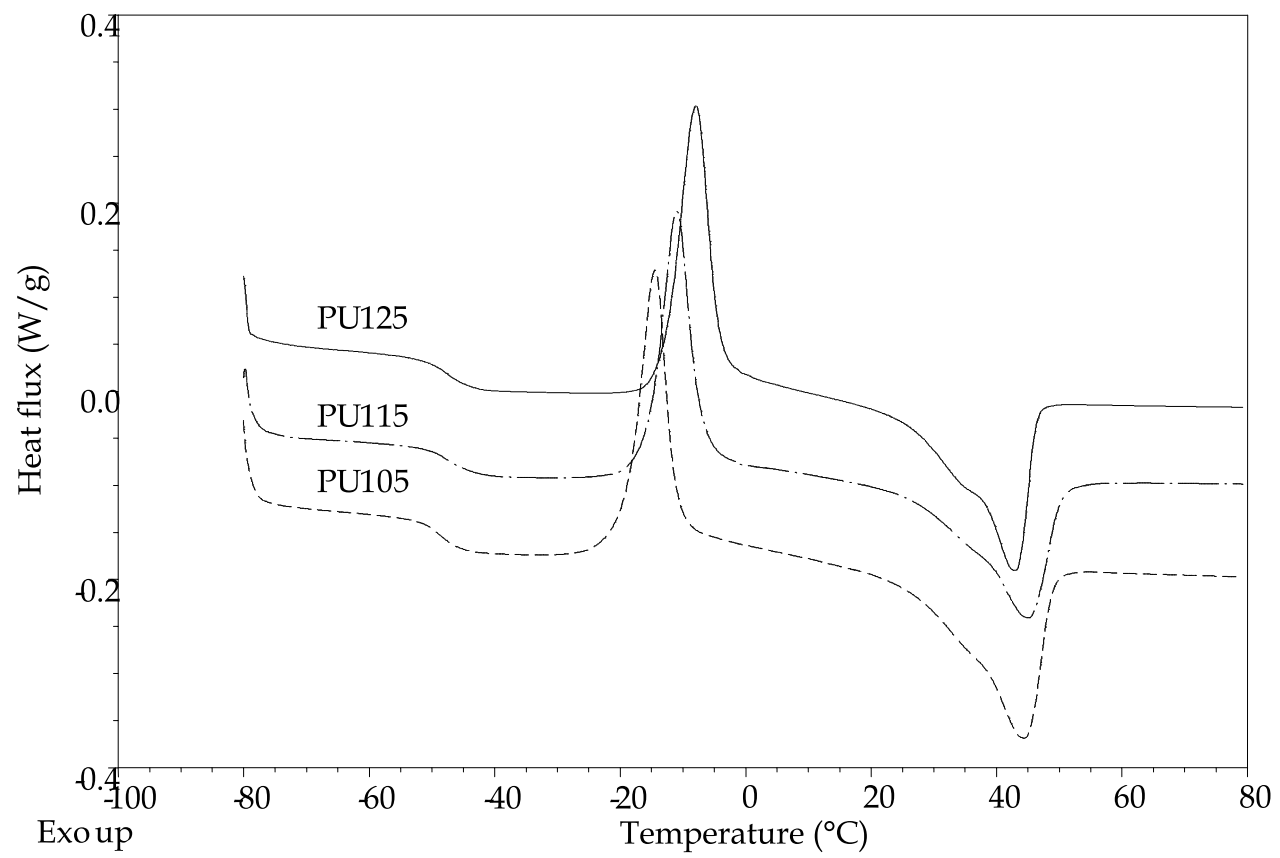

Fig. 7. DSC thermograms of synthesized thermoplastic polyurethanes (TPU) with different $\mathrm{NCO} / \mathrm{OH}$ and silica.

Other properties affected by the presence of fumed silica are the enthalpy and crystallization temperature (Figures 9 and 10). During the first scan of DSC, the material is softened to $80{ }^{\circ} \mathrm{C}$ and is then rapidly cooled to $-80{ }^{\circ} \mathrm{C}$ to fix the polymer chains, so that during the second sweep of temperature changes can be observed related energy with the crystal structure of the material. 


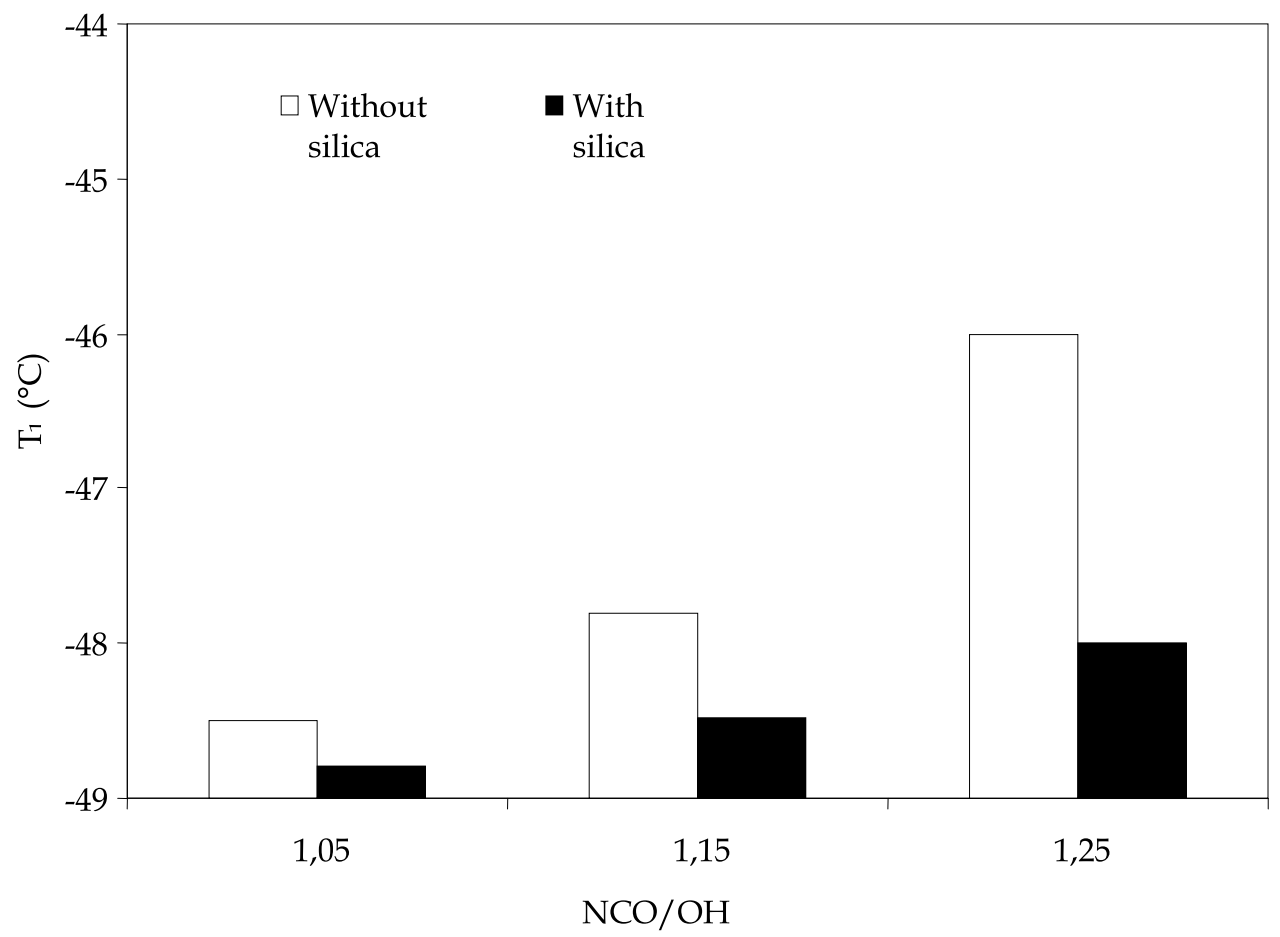

Fig. 8. Tg values of samples with different $\mathrm{NCO} / \mathrm{OH}$ and with -without silica.

To compare TPU's without silica, when $\mathrm{NCO} / \mathrm{OH}$ is increased, crystallization enthalpy decreases. Also, cold crystallization process occurs at higher temperatures. PU105 without silica has highest enthalpy of crystallization, -the crystallization process is more exothermic and it occurs at a lower temperature-. In TPU, to have a lower DPS, are favored interactions between hard and soft segments, which are energetically more favorable than those observed between the soft segments themselves. By increasing the NCO/OH in TPU's without silica, the DPS increase and establish more interactions between soft segments, which have less power than earlier, and the crystallization enthalpy decreases relative to that of PU105 without silica, and the process crystallization is observed at higher temperatures. PU125 sample without silica has therefore lower enthalpy of crystallization and the crystallization process is observed at higher temperatures.

Also, samples containing fumed silica, with increasing $\mathrm{NCO} / \mathrm{OH}$ increase the enthalpy of crystallization and cold crystallization process is observed at lower temperatures. This is because the main interactions that are established in polyurethanes with silica correspond to soft segment-soft segment due to increased phase segregation with respect to TPU's without silica, which affects the association-dissociation equilibrium of hydrogen bonding. So polyurethane sample with higher DPS is more affected by the presence of silica (PU125) and has the highest enthalpy of crystallization temperature and crystallization occurs at lower values for PU115 and PU105. Finally, we observe that TPU's without silica, release more energy during heating process comparing with samples with silica. Also, the cold 
crystallization process of polyurethane is observed at a lower temperature. This is because the samples without silica have a lower DPS.

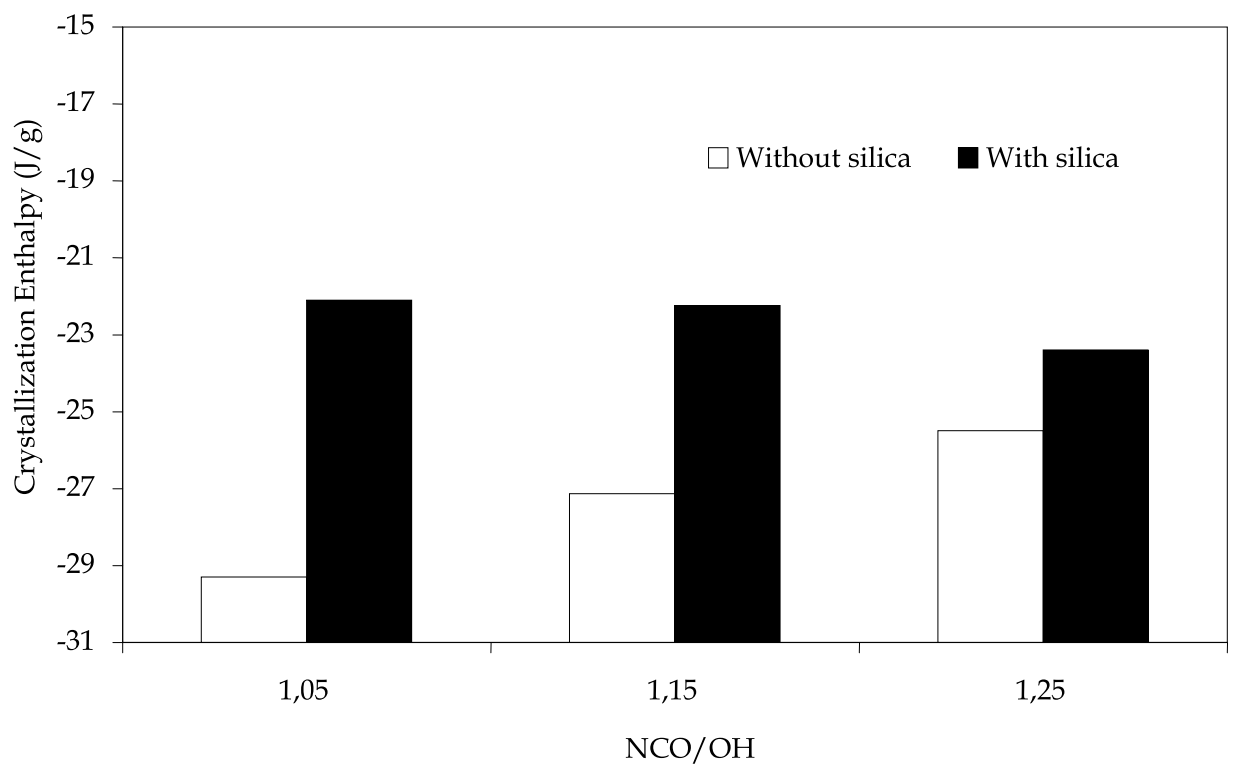

Fig. 9. Enthalpy of crystallization and cold crystallization of samples with different $\mathrm{NCO} / \mathrm{OH}$ and with -without silica.

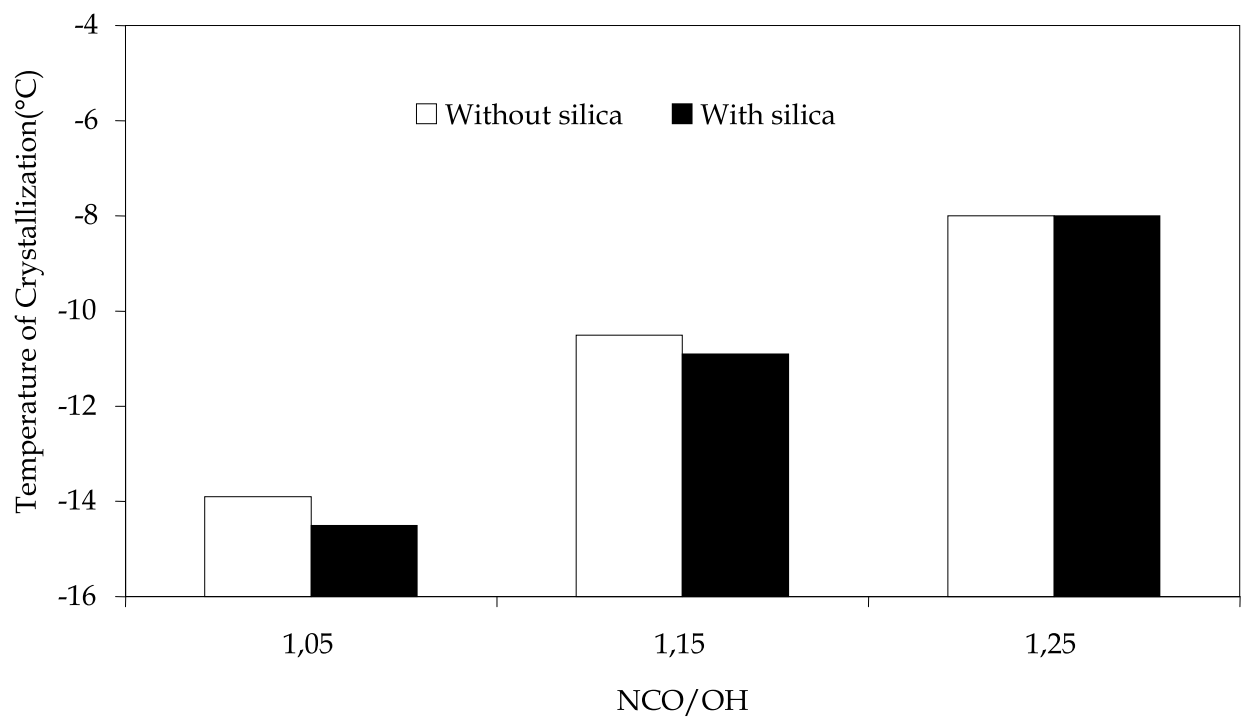

Fig. 10. Temperature of crystallization of samples with different $\mathrm{NCO} / \mathrm{OH}$ and with without silica. 
During fusion enthalpy (softening) in TPU's without silica, the melting enthalpy decreases with increasing $\mathrm{NCO} / \mathrm{OH}$, as a result of increased phase segregation of polyurethane, and it is necessary to apply a lower energy content to achieve softening of the polyurethane. PU105 without silica has the highest melting enthalpy, - process that needs more energy to soften the polymer - and as expected, there is a greater melting temperature. In TPU's with lower DPS, are favored interactions between hard and soft segments, which are energetically more favorable than those, observed between the soft segments themselves. By increasing the $\mathrm{NCO} / \mathrm{OH}$ in TPU's without silica, DPS increase and establish more interactions between soft segments, which have less energy than before, and so the melting enthalpy decreases and the melting process occurs at lower temperatures. PU125 sample without silica has therefore lower enthalpy of fusion. In this case, the difference between the melting temperatures in TPU's without silica with different $\mathrm{NCO} / \mathrm{OH}$ is not significant.

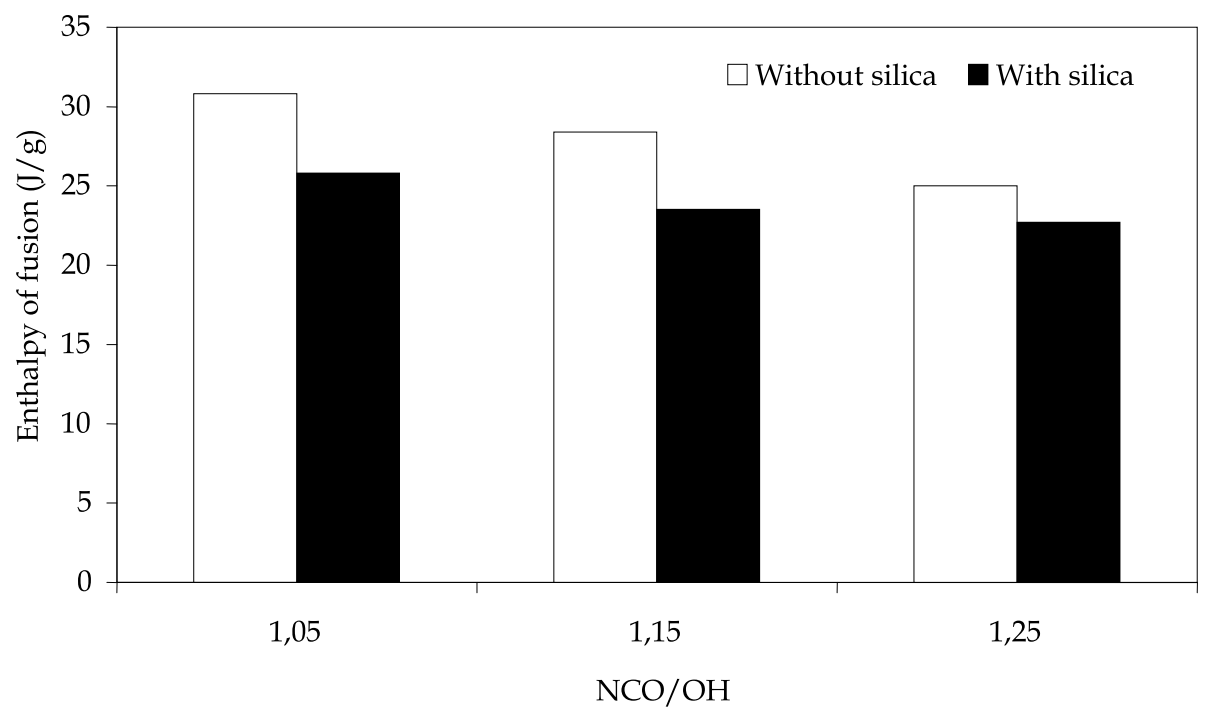

Fig. 11. Enthalpy of fusion of samples with different $\mathrm{NCO} / \mathrm{OH}$ and with -without silica.

In polyurethanes containing fumed silica, with increasing $\mathrm{NCO} / \mathrm{OH}$, the melting enthalpy decreases and the softening process occurs at lower temperatures. This is because the main interactions that are established in TPU with silica correspond to the soft segments themselves, due to increased phase segregation due to the effect of the presence of silica on the association-dissociation equilibrium hydrogen bond. So, TPU with higher DPS, is more affected by the presence of silica (PU125) and has the lowest melting enthalpy and melting temperature is observed at lower values for other TPU's with silica.

Finally, polyurethanes do not contain silica; require more energy during the heating process to melt for TPU's with silica. Also, the merger of polyurethane without silicon is observed at a higher temperature than the samples containing hydrophilic silica. This is because the samples without silica have a lower DPS, thus favoring interactions between hard and soft segments, which are energetically stronger than those, observed between the soft segments in TPU's themselves with silica, as required more energy for melting. 
Also, It was used X-ray diffraction (XRD). Results show -as in previous studies-, significant diffraction peaks at $2 \theta=20^{\circ}$ and $2 \theta=25^{\circ}$ (without silica). TPU's with silica present three main reflections at $2 \theta:\left(21.2^{\circ}-21.7^{\circ}\right), 2 \theta$ : $\left(22.2^{\circ}-22.4^{\circ}\right)$ and $2 \theta\left(24.1^{\circ}\right.$ to $\left.24.6^{\circ}\right)$. Some reflections of (101) are insignificant, so it was not possible to quantify.

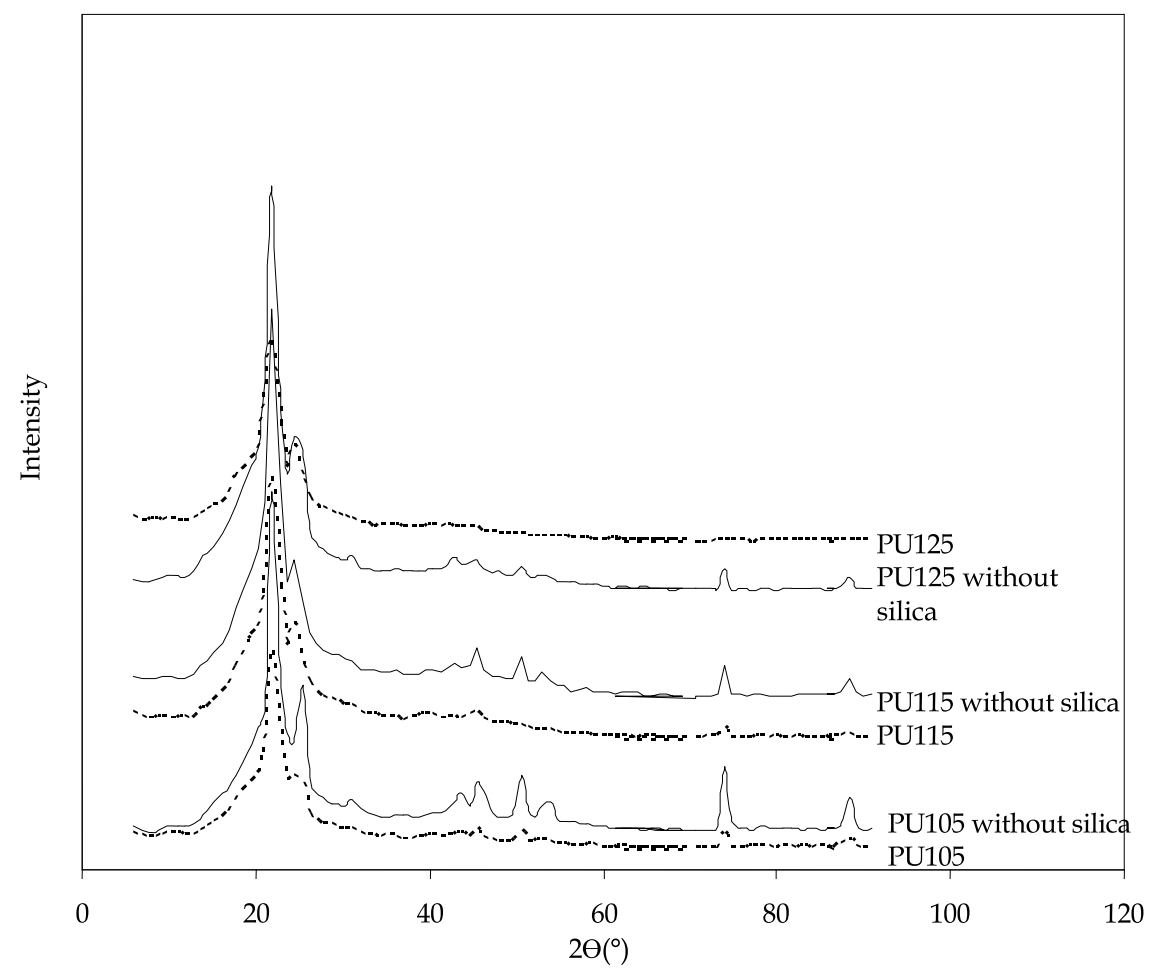

Fig. 12. X-ray diffraction (XRD) of samples with different $\mathrm{NCO} / \mathrm{OH}$ and with -without silica.

\section{Conclusions}

The morphological study of polyurethanes without silica indicates that the increase of NCO / $\mathrm{OH}$ increases the degree of phase segregation (DPS), due to the effect of repulsion that exists between the polar hard segments of polyurethane and non-polar chains polyol. With the addition of hydrophilic silica to polyurethane, the degree of phase separation is favored in all polyurethanes, indicating a possible interaction of silica silanol groups by hydrogen bonds with the polymer.

\section{References}

Jaúregui-Beloqui, B., Fernández-García, J.C., Orgilés-Barceló, A.C., Mahiques-Bujanda, M.M. \& Martín-Martínez, J.M. (1999). Thermoplastic polyurethane-fumed silica composites: influence of the specific surface area of fumed silica on the viscoelastic and adhesion properties. Journal of Adhesion Science and Technology, 13, pp. 695-711, 0169-4243. 
Jaúregui-Beloqui, B., Fernández-García, J.C., Orgilés-Barceló, A.C., Mahiques-Bujanda, M.M. \& Martín-Martínez, J.M. (1999). Rheological properties of thermoplastic polyurethane adhesive solutions containing fumed silicas of different surface areas. International Journal of Adhesion and Adhesives, 19, pp. 321-328, 0143-7496.

Maciá-Agulló, T.G., Fernández-García, J.C., Pastor-Sempere, N., Orgilés-Barceló, A.C. \& Martín-Martínez. J.M. (1992). Addition of Silica to Polyurethane Adhesives. Journal of Adhesion, 38, pp. 31-53, 0021-8464.

Navarro-Bañón, V., Vega-Baudrit, J., Vázquez, P. \& Martín-Martínez, J.M. (2005). Interactions in Nanosilica-Polyurethane Composites Evidenced by Plate-Plate Rheology and DMTA. Macromolecular Symposia, 221, pp. 1, 1022-1360.

Nunes, R.C.R., Fonseca, J.L.C.M. \& Pereira, M.R. (2000). Polymer-filler interactions and mechanical properties of a polyurethane elastomer. (2000). Polymer Testing, 19, pp. 93-103, 0142-9418.

Nunes, R.C.R., Pereira, R.A., Fonseca, J.L.C. \& Pereira, M.R. (2001). X-ray studies on compositions of polyurethane and silica. Polymer Testing, 20, pp. 707-712, 0142-9418.

Oertel, G. (1993). Polyurethane Handbook 2nd. Hanser: New York, pp. 7-116. 3-446-17198-3.

Pérez-Limiñana, M.A., Torró-Palau, A.M., Orgilés-Barceló, A.C. \& Martín-Martínez, J.M. (2001). Rheological properties of polyurethanes adhesives containing silica as filler; influence of the nature and surface chemistry of silica. Macromolecular Symposia, 169, pp. 191-196, 1022-1360.

Sánchez-Adsuar, M.S., Papón, E. \& Villenave, J. (2000). Influence of the prepolymerization on the properties of thermoplastic polyurethane elastomers. Part I. Prepolimerization characterization. Journañ of Applied Polymer Science, 76, pp. 15961601, 0021-8995.

Tien Y. \& Wei K. (2001). Hydrogen bonding and mechanical properties in segmented montmorillonite/polyuretane nanocomposites of different hard segment ratios. Polymer, 42, pp. 3213-3221, 0032-3861.

Torró-Palau, A., Fernández-García, J.C., Orgilés-Barceló, A.C. \& Martín-Martínez, J.M. (2001). Characterization of polyurethanes containing different silicas. International Journal of Adhesion and Adhesives, 21, pp. 1-9, 0143-7496.

Vega-Baudrit, J., Navarro-Bañon, V., Vázquez, P. \& Martín-Martínez, J.M. (2006). Properties of thermoplastic polyurethane adhesives containing nanosilicas with different specific surface area and silanol content. International Journal of Adhesion and Adhesives, 27, pp. 469-479, 0143-7496.

Vega-Baudrit, J., Sibaja-Ballestero, M., Vázquez, P., Navarro-Bañón, V., Martín-Martínez, J.M. \& Benavides, L. (2005). Kinetics of Isothermal Degradation Studies in Adhesives by Thermogravimetric Data: Effect of Hydrophilic Nanosilica Fillers on the Thermal Properties of Thermoplastic Polyurethane-Silica Nanocomposites. Recent Patents on Nanotechnology, 2(3), pp. 220-226, 1872-2105.

Vega-Baudrit, J., Sibaja-Ballestero, M. \& Martín-Martínez, J.M. (2009). Study of the Relationship between Nanoparticles of Silica and Thermoplastic Polymer (TPU) in Nanocomposites. Journal of Nanotechnology Progress International. (JONPI), 1, pp. 2434, 1941-3475. 


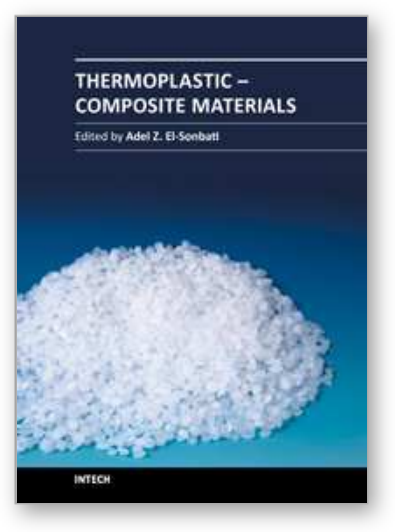

\author{
Thermoplastic - Composite Materials \\ Edited by Prof. Adel El-Sonbati
}

ISBN 978-953-51-0310-3

Hard cover, 146 pages

Publisher InTech

Published online 16, March, 2012

Published in print edition March, 2012

Composite materials often demand a unique combination of properties, including high thermal and oxidative stability, toughness, solvent resistance and low dielectric constant. This book, "Thermoplastic - Composite Materials", is comprised of seven excellent chapters, written for all specialized scientists and engineers dealing with characterization, thermal, mechanical and technical properties, rheological, morphological and microstructure properties and processing design of composite materials.

\title{
How to reference
}

In order to correctly reference this scholarly work, feel free to copy and paste the following:

José Vega-Baudrit, Sergio Madrigal Carballo and José Miguel Martín Martínez (2012). Thermoplastic Polyurethanes-Fumed Silica Composites: Influence of $\mathrm{NCO} / \mathrm{OH}$ in the Study of Thermal and Rheological Properties and Morphological Characteristics, Thermoplastic - Composite Materials, Prof. Adel El-Sonbati (Ed.), ISBN: 978-953-51-0310-3, InTech, Available from: http://www.intechopen.com/books/thermoplasticcomposite-materials/thermoplastic-polyurethanes-fumed-silica-composites-influence-of-nco-oh-in-the-study-ofthermal-and-

\section{INTECH}

open science | open minds

\section{InTech Europe}

University Campus STeP Ri Slavka Krautzeka 83/A 51000 Rijeka, Croatia Phone: +385 (51) 770447

Fax: +385 (51) 686166 www.intechopen.com

\section{InTech China}

Unit 405, Office Block, Hotel Equatorial Shanghai No.65, Yan An Road (West), Shanghai, 200040, China 中国上海市延安西路65号上海国际贵都大饭店办公楼 405 单元 Phone: $+86-21-62489820$

Fax: $+86-21-62489821$ 
(C) 2012 The Author(s). Licensee IntechOpen. This is an open access article distributed under the terms of the Creative Commons Attribution 3.0 License, which permits unrestricted use, distribution, and reproduction in any medium, provided the original work is properly cited. 